\title{
Program for Contact Allergen Research (PPAC) - a new tool for dermatologists ${ }^{*}$
}

\author{
Vanessa Barreto Rocha ${ }^{1}$ \\ Flávia Vasques Bittencourt ${ }^{1}$
}

\author{
Carla Jorge Machado ${ }^{1}$
}

DOI: http:/ /dx.doi.org/10.1590/abd1806-4841.20164604

\begin{abstract}
In Brazil there is no classification of dermatological products by the presence of vehicles with sensitizing potential. The objective of this study is to create a database to classify such products based on the absence of the selected allergens, aiming at making it available for medical consultation. We conducted an observational study, from the content of labels and/or inserts on the composition of 966 dermatological products in the Brazilian market. No chemical analysis was performed. The database called Programa para Pesquisa de Alérgenos de Contato (www.ppac.com.br) was created, in which safe products for patients allergic to dermatological vehicles are provided.
\end{abstract}

Keywords: Additives in cosmetics; Dermatitis, allergic contact; Preservatives, pharmaceutical

Many of the preservatives and fragrances with known sensitization potential are commonly found in vehicles of dermatological products, and its importance is not widely disseminated to physicians. ${ }^{1-4}$

Allergic contact dermatitis (ACD) to preservatives and fragrances is a major cause of dermatological consultations. ${ }^{1}$ Thus, the communication of the ingredients of these products is the basis for prevention of ACD to these substances. ${ }^{4-6}$

In other countries, there are databases for consultation by dermatologists, such as CAMP (Contact Allergen Management Program), maintained by the American Contact Dermatitis Society, and CARD (Contact Allergen Replacement Database), of Mayo Clinic. ${ }^{7,8}$ CARD and CAMP are digital tools designed to help the allergic patient, wherein lists of products free of certain substances are generated and, despite not being exhaustive, they are excellent starting points for education and/or prescription for these patients. ${ }^{8}$ These programs provide lists of personal products and dermatological medicines that are safe for the allergic patient.

In Brazil, such database does not exist, and it is infeasible to use the mentioned bases in the country, because they do not include most of the products available here. Thus the objective of this study was to provide a Brazilian database for medical consultation, enabling identification of products in which such allergens are present, optimizing prescription and avoiding potential events in iatrogenic patients with ACD.

Review studies on ACD for dermatological vehicles have resulted in a list of allergens present in products: sorbic acid, cetyl alcohols, cetostearyl, stearyl and stearic alcohol, balsam of Peru, butylated hydroxytoluene (BHT), bronopol, chlorhexidine, diazolidinyl urea, ethylene diamine, phenoxyethanol, 
formaldehyde, fragrance, imidazolidinyl urea, lanolin, methylchloroisothiazolinone/ methylisothiazolinone (MCI/MI), methyldibromo glutaronitrile, parabens, propylene glycol, triclosan and triethanolamine. ${ }^{1-4}$ As for the fragrance, the 26 ingredients contained in the European Cosmetics Directive were included, ${ }^{6}$ as well as the hidden ingredients of fragrance and all botanical substances for its possible action as sensitizing. ${ }^{9}$ Balsam of Peru was considered synonymous with fragrance. ${ }^{1}$

We obtained 966 labels and package inserts of dermatological products, divided into "brand" and generic topical medications, injectable pharmaceuticals, sunscreens, moisturizers, soaps and cleansing lotions, shampoos and cosmeceuticals. The selection of drugs was made possible by consulting the Dictionary of Pharmaceutical Specialties (DEF). Package in- serts were consulted on the DEF itself, on laboratories websites, thought questions sent by e-mail to these laboratories or were direct obtained from medicines. For generic drugs, we performed a research on generic dermatological products laboratories websites and we selected six who had complete package inserts available online. In the case of products classified as "non-medicine", we tried to obtain the information on the industries websites, but most of the time, the information was not available. Labels and package inserts were obtained upon request to the industry by email or to their representatives, and most of the information came from free samples obtained during 12 years of work.

The Program for Contact Allergen Research (PPAC) was created, and it is available at www.ppac. com.br, in which lists of products without the allergen $\leftarrow=$ C D www.ppac.com.br/associado/produtos/pesquisar

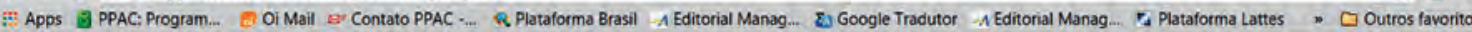

\section{PPAC Programa para Pesquisa de Alérgenos de Contato}

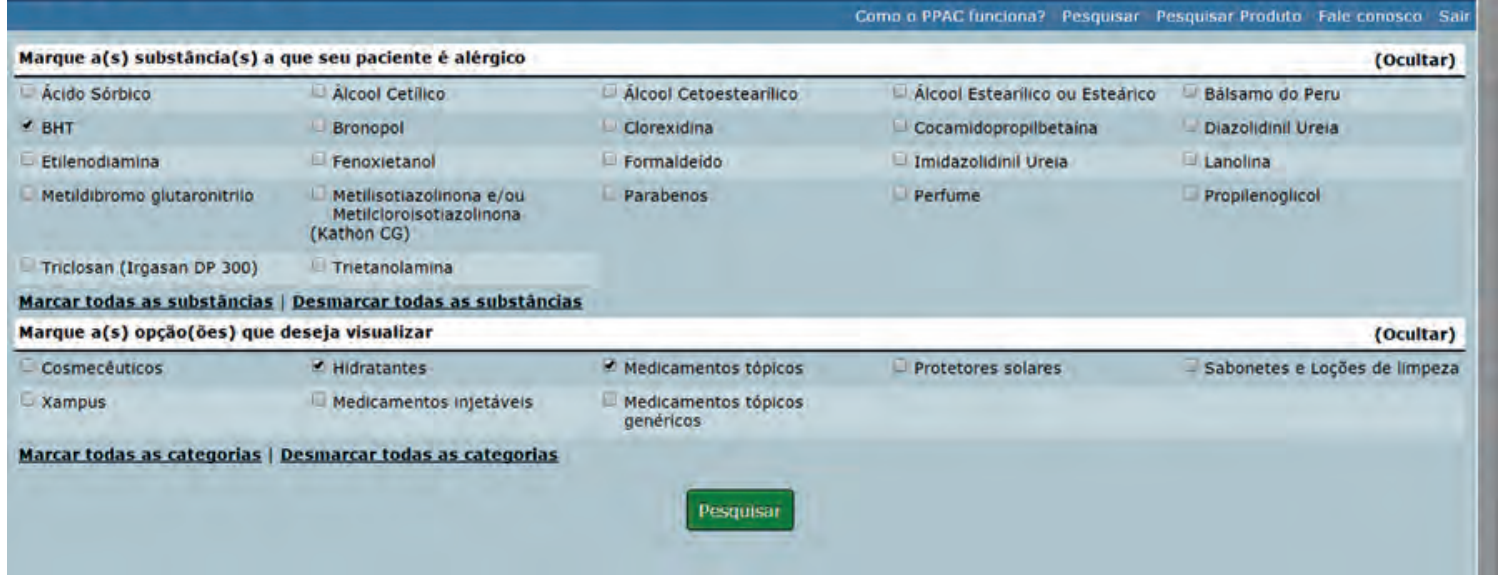

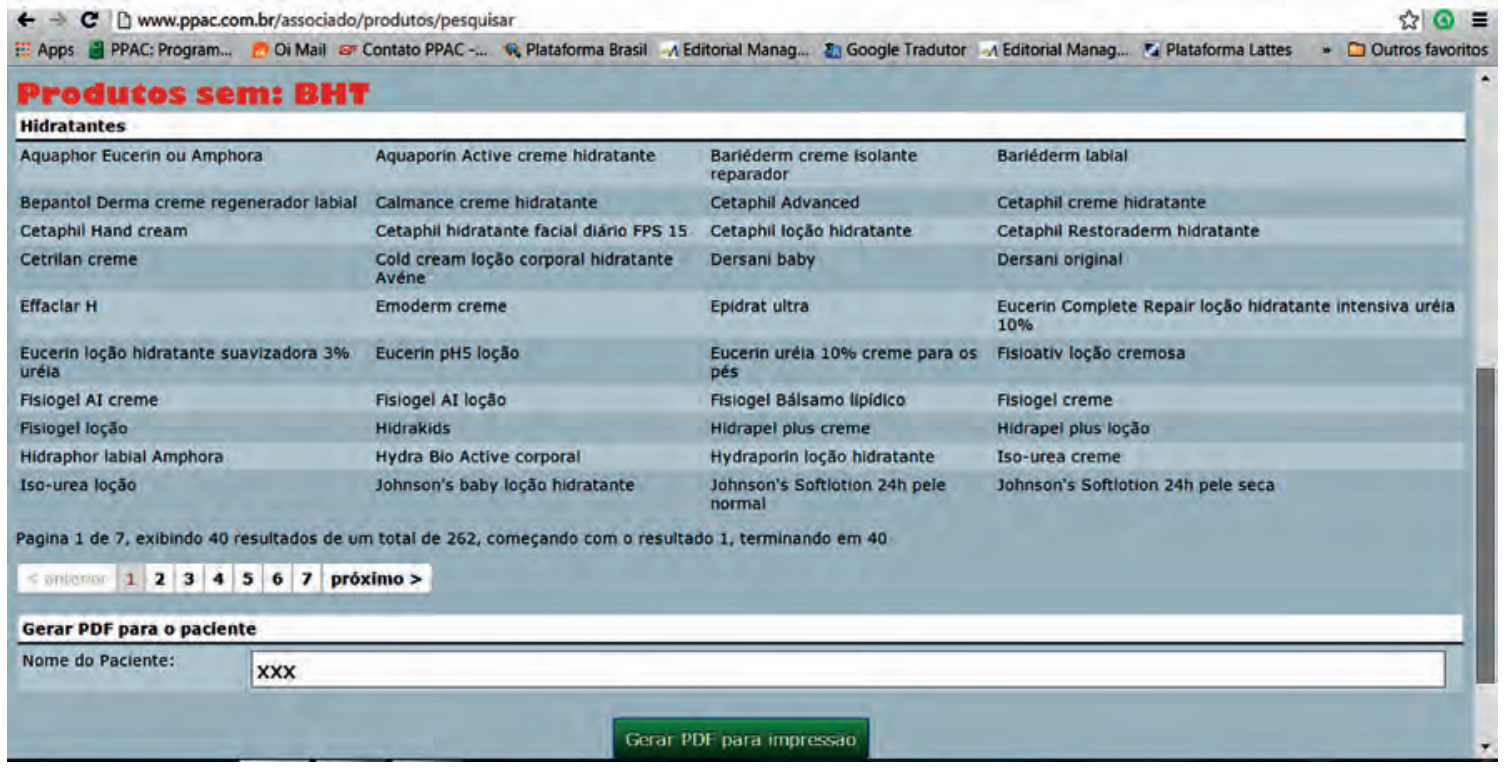

Figure 1 :

Search in PPAC for moisturizers and drugs without BHT
Figure 2 :

Partial result of search for products without BHT on PPAC 
in question are generated (Figures 1 and 2).

It is important for the physicians the recognition of medical risk of allergy to the components of dermatological vehicles, particularly for patients who do not respond adequately to the prescribed treatment. ${ }^{1,2}$ Usually, in the end of the contact test, when relevant allergens present in products for personal care are identified, the physician asks the patient to read its composition to avoid topical products free from that allergen.

Typical names of allergens are long, difficult to pronounce, making it difficult to adhere the treatment. When prescribing for an allergic patient, the physician should be aware of all product components, information currently available only through consultation to each label/ package insert.

The information of the product ingredients is the basis for preventing ACD to these substances. 5,8 Therefore, the creation of the PPAC database can be very useful to dermatologists. By using it, the physician chooses the allergen that should be avoided and the class of products he/she wants to prescribe, and the program creates lists of safe products for allergic patient use. One can also simultaneously select multiple allergens for patients with ACD to multiple substances, and then an intersection of these data is conducted.

The absence of papers on the subject in Brazil makes it difficult to compare it with the literature.

One challenge faced in the study was the legibility of package inserts, hampered by the size and type of fonts, as already reported by other authors, and several synonyms that the ingredients have, which are not yet fully standardized. ${ }^{10}$

Another major difficulty was the recent Americanization of names of dermatological products, which have become extensive, with very similar names, sometimes even in French.

Contact with the industry, in order to educate them to disclose the ingredients of the products used in the prescription to allergic patients, has been difficult.

We expect that, from this study, there is awareness and facilitation of contact with the pharmaceutical industry to improve access to information of the ingredients of dermatological products.

There may be disagreement regarding the class of each product. An example of this is a cosmeceutical with sunscreen, which can be allocated in both classes. An attempt was made, however, to detect the extent to which the product is used, among other aspects, to better classify it.

The composition of products can change and although this study has been submitted to all companies that provided the labels/package inserts, rarely the change in the composition of the topical products has been reported.

With the creation of the PPAC, lists of dermatological products without the presence of certain allergens are provided, and this program is already available for consultation by dermatologists.

\section{REFERENCES}

1. Rietschel R, Fowler J. Fisher's Contact Dermatitis. 6th ed. Hamilton: BC Decker Inc; 2008.

2. Yazar K, Johnsson S, Lind ML, Boman A, Lidén C. Preservatives and fragrances in selected consumer-available cosmetics and detergents. Contact Dermatitis. 2011;64:265-72

3. Warshaw EM, Belsito DV, DeLeo VA, Fowler JF Jr, Maibach HI, Marks JG, et al. North American Contact Dermatitis Group patch-test results, 2003-2004 study period. Dermatitis. 2008;19:129-36.

4. Flyvholm MA. Preservatives in registered chemical products. Contact Dermatitis. 2005:53:27-32.

5. Uter W, Johansen JD, Börje A, Karlberg AT, Lidén C, Rastogi S, et al. Categorization of fragrance contact allergens for prioritization of preventive measures: clinical and experimental data and consideration of structure-activity relationships. Contact Dermatitis. 2013;69:196-230.

6. Cheng J, Zug KA. Fragrance allergic contact dermatitis. Dermatitis. 2014;25:232-45

7. Yiannias JA, el-Azhary RA. Contact Allergen Avoidance Program: Topical Skin Care Product Database. Am J Contact Dermat. 2000;11:243-7.

8. Alani Jl, Davis MD, Yiannias JA. Allergy to cosmetics: a literature review. Dermatitis. 2013:24:283-90.

9. Scheinman PL. Exposing covert fragrance chemicals. Am J Contact Dermat. 2001;12:225-8.

10. Yazar K, Seimyr GÖ, Novak JA, White IR, Lidén C. Readability of product ingredient labels can be improved by simple means: an experimental study. Contact Dermatitis. 2014;71:233-41.
MAILING ADDRESS:
Vanessa Barreto Rocha
Al. Álvaro Celso, 55
Santa Efigênia
30150-260 - Belo Horizonte - MG
Brazil
Email:vanessabarreto@oi.com.br

How to cite this article: Rocha VB, Machado CJ, Bittencourt FV. Program for Contact Allergen Research (PPAC) - A new tool for dermatologists. An Bras Dermatol. 2016:91(3):390-2. 